\title{
A Lower Bound on SINR Threshold for Call Admission Control in Multiple-Class CDMA Systems with Imperfect Power-Control
}

\author{
Mohamed H. Ahmed \\ Faculty of Engineering and Applied Science \\ Memorial University of Newfoundland \\ St. John's, Canada \\ mhahmed@engr.mun.ca
}

\author{
Halim Yanikomeroglu \\ Broadband Communications \& Wireless Systems Centre \\ Carleton University \\ Ottawa, Canada \\ halim@sce.carleton.ca
}

\begin{abstract}
Call admission control (CAC) is essential to guarantee the signal quality in CDMA systems. Signal-to-interference-andnoise ratio (SINR) is used as the criterion for user admission by comparing the SINR with a predefined threshold value $\left(S I N R_{\mathrm{th}}\right)$. Lowering this threshold level is desirable to reduce the blocking rate. However, a lower bound of $S I N R_{\text {th }}$ is vital to keep the outage probability $\left(P_{\text {out }}\right)$ below a maximum value. In this paper, we derive this lower bound of $\operatorname{SINR}_{\mathrm{th}}\left(S I N R_{\mathrm{th}-\mathrm{lb}}\right)$ for multi-class CDMA systems with imperfect power control. $S I N R_{\text {th-lb }}$ of class $i$ $\left(S I N R_{\text {th-lb }}(i), i=1,2, \ldots, L\right)$ is determined by finding the relationship between $P_{\text {out }}(\mathrm{i})(i=1,2, \ldots ., L)$ and $\operatorname{SIN} R_{\mathrm{th}}(i)(i=1,2, \ldots .$. $L)$ where $L$ is the number of classes. Then, $\operatorname{SIN} R_{\text {th-lb }}(i)$ is

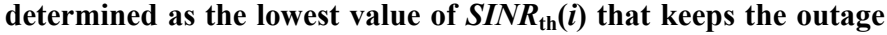
probability of all classes below the corresponding maximum values.
\end{abstract}

Keywords-Call admission control; imperfect power control; multiple-class CDMA systems

\section{INTRODUCTION}

Unlike TDMA/FDMA systems, CDMA systems have soft capacity limits. This means that the higher the system loading, the worse the signal quality the users can get. Hence, call admission control (CAC) is usually used in CDMA networks to limit the system loading in order to preserve the signal quality. Signal to interference and noise ratio (SINR) based $\mathrm{CAC}$ is proposed in the literature as an effective technique to guarantee the signal quality in terms of a minimum SINR $\left(S I N R_{\min }\right)$ for admitted users (e.g. [1, 2]). $S I N R_{\min }$ is corresponding to the maximum tolerable bit error rate (BER). In these CAC schemes, SINR of the reverse link is measured and then compared with a predefined threshold value $\left(S I N R_{\mathrm{th}}\right)$. The incoming call is admitted only if the measured SINR is higher than $\operatorname{SINR}_{\mathrm{th}}$.

Perfect power control is usually assumed in the reverse link of CDMA systems such that the received power and SINR are kept constant for all users regardless of their locations or channel conditions. In reality, however, the received power and SINR fluctuate around the targeted values due to power control command errors and delay. It has been shown that SINR in this case can be modeled by the lognormal distribution $[3,4]$.
If perfect power control would be realizable, $S I N R_{\text {th }}$ can be chosen equal to $S I N R_{\min }$. Due to the SINR fluctuations, however, $\operatorname{SINR}_{\mathrm{th}}$ has to be carefully chosen. A high value of $S I N R_{\text {th }}$ can lead to a low outage probability $\left(P_{\text {out }}=P\left(\operatorname{SINR}<\operatorname{SIN} R_{\min }\right)\right)$ but at the expense of a high blocking probability $\left(P_{\mathrm{b}}\right)$. On the other hand, a low value of $S I N R_{\mathrm{th}}$ can reduce $\left(P_{\mathrm{b}}\right)$ but with a high outage probability. This is because PC becomes infeasible if the number of admitted users per cell exceeds a certain limit. If PC turns out to be infeasible, $P_{\text {out }}$ increases since SINR converges to a lower level than the target value $\left(S I N R_{\mathrm{trg}}\right)$ as shown in Fig. 1. It has to be emphasized, though, that outage $\left(S I N R<S I N R_{\min }\right)$ can also take place (but with a much smaller probability compared to the infeasible PC case) even if PC is feasible due to SINR fluctuation around the target value as depicted in Fig. 1.

A higher bound of $\operatorname{SINR}_{\mathrm{th}}$ has been derived in [5] such that $P_{\mathrm{b}}$ can be kept below a maximum value. In [6], we have derived a lower bound of $\operatorname{SINR}_{\mathrm{th}}\left(\operatorname{SINR}_{\mathrm{th}-\mathrm{lb}}\right)$ in single-class CDMA networks. In this paper, we extend the work presented in [6] to the case of multi-class CDMA networks. The lower bound is derived such that the outage probabilities of all classes are kept below specified values. The derivation of $S I N R_{\text {th-1b }}$ is presented in Section II. Then, the results for a dualclass case are presented in Section III. Finally, conclusions are given in Section IV.

\section{LOWER BOUND OF SINR THRESHOLD}

The lower bound of $\operatorname{SINR}_{\mathrm{th}}\left(\operatorname{SINR}_{\mathrm{th}-\mathrm{l}}\right)$ is determined using the following steps:

- The outage probability of class $i\left(P_{\text {out }}(i)\right)$ is determined as a function of $\operatorname{SINR}_{\mathrm{th}}(i), \operatorname{SINR}_{\min }(i)$, mean and standard deviation of $\operatorname{SINR}(i)$ and mean traffic intensity (for all classes, i.e. for all values of $i$ ).

- The mean of $\operatorname{SINR}(i)$ is determined while other parameters $\left(\operatorname{SINR}_{\min }(i)\right.$, standard deviation of $\operatorname{SINR}(i)$ and mean traffic intensity) are assumed to be given.

- $\operatorname{SINR}_{\mathrm{th}-\mathrm{lb}}(i)$ is determined as the lowest value of $\operatorname{SINR}_{\mathrm{th}}(i)$ that keeps $P_{\text {out }}(i)$ (for all values of $i$ ) below the maximum acceptable value $\left(P_{\text {out } \max }(i)\right)$. 


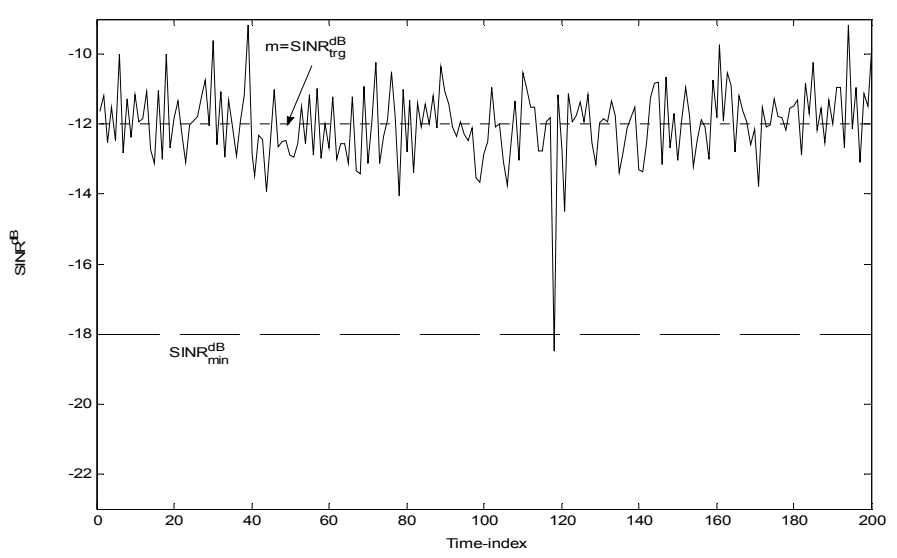

(a)

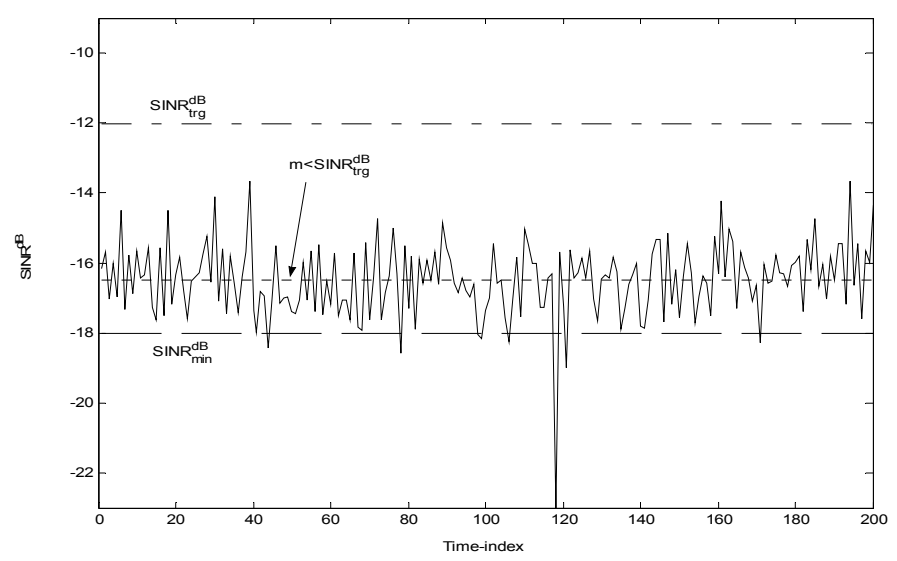

(b)

Fig. 1. SINR fluctuations around the mean value (a) feasible PC (b) infeasible PC.

Assuming the numbers of users in different classes are independent random variables, the outage probability of class $i$ $\left(P_{\text {out }}(i)\right)$ can be expressed as

$$
P_{\text {out }}(i)=\sum_{N_{L}}^{\infty} \cdots \sum_{N_{2}=1}^{\infty} \sum_{N_{1}=1}^{\infty} P_{\text {out } \mid N_{1}, N_{2}, \ldots, N_{L}}(i) P\left(N_{1}\right) P\left(N_{2}\right) \cdots P\left(N_{L}\right)
$$

where $P_{\text {out } \mid N_{1}, N_{2}, \ldots, N_{L}}(i)$ is the conditional outage probability of class $i$ given the number of active users (per cell) in all classes $\left(N_{1}, N_{2}, \ldots, N_{L}\right)$ and $L$ is the number of classes. With imperfect PC, SINR can be modeled as a lognormallydistributed random process. Hence, $P_{\text {out } \mid N_{1}, N_{2}, \ldots, N_{L}}(i)$ can be expressed as

$$
P_{\mathrm{out} \mid N_{1}, N_{2}, \ldots, N_{L}}=1-Q\left(\frac{\operatorname{SINR}_{\min }^{\mathrm{dB}}(i)-m(i)}{\sigma(i)}\right)
$$

where $m(i)$ and $\sigma(i)$ are the mean and the standard deviation of $\operatorname{SINR}^{\mathrm{dB}}(i)$, respectively where the $\mathrm{dB}$ superscript denotes that SINR is expressed in dBs.

As shown in Fig. 1, when PC is feasible, $m(i)$ converges to the target SINR value ( $\operatorname{SINR}_{\operatorname{trg}}^{\mathrm{dB}}(i)$ ), but when PC becomes infeasible $m(i)$ starts to degrade and its value depends on the number of active users in different classes $\left(N_{l}, N_{2}, \ldots, N_{L}\right)$. Hence, $m(i)$ can be expressed as

$$
m(i)=\left\{\begin{array}{l}
\operatorname{SINR}_{\mathrm{trg}}^{\mathrm{dB}}(i) \quad N_{i} \leq N_{i}^{\max } \\
\operatorname{lol}_{\log }\left(\frac{1}{\left(N_{i}-1\right)(1+f)+\sum_{\substack{j=1 \\
j \neq i}}^{L} R_{j i} N_{j}+\left(\eta_{o} W / S_{i}\right)}\right)
\end{array} N_{i}>N_{i}^{\max }\right.
$$

where $f$ is the ratio of the inter-cell interference to the intracell interference, $R_{j i}$ is the ratio of the received power of class $j$ to that of class $i, \eta_{o}$ is the noise power spectral density, $W$ is the spreading bandwidth, $S_{i}$ is the target balanced received power level of class $i$ and $N_{i}^{\max }$ is the maximum number of users in class $i$ given the number of users in other classes $\left(N_{j}\right.$ $\forall j \neq i$ ). It can be shown that $R_{j i}$ is given by [7]

$$
R_{j i}=\frac{\operatorname{SINR}_{\mathrm{trg}}(j)}{1+(1+f) \operatorname{SINR} R_{\mathrm{trg}}(j)} \frac{1+(1+f) \operatorname{SINR}_{\mathrm{trg}}(i)}{\operatorname{SINR}_{\mathrm{trg}}(i)}
$$

while $N_{i}^{\max }$ can be shown (using a similar analysis to that given in [8]) to be given by

$$
N_{i}^{\max }=\max \left(\left\lfloor 1+\frac{1}{(1+f)}\left(\frac{1}{\operatorname{SINR}_{\mathrm{trg}}(i)}-\frac{\eta_{o} W}{S_{i}}\right)-\sum_{\substack{j=1 \\ j \neq i}}^{L} R_{j i} N_{j}\right\rfloor, 0\right)
$$

It is apparent from (2)-(5) that $P_{\mathrm{out} \mid N_{1}, N_{2}, \ldots, N_{L}}(i)$ is constant and does not depend on the number of users in different classes $\left(N_{l}, N_{2}, \ldots, N_{L}\right)$ as long as PC is feasible. When PC becomes infeasible, $P_{\text {out } \mid N_{1}, N_{2}, \ldots, N_{L}}(i)$ increases monotonically by the increase of the number of users. This trend is shown in Fig. 2 for the dual class case $(L=2)$.

Since the number of class $i$ users per cell $\left(N_{i}\right)$ can be modeled as a Poisson process, $P\left(N_{i}\right)$ in (1) is given by

$$
P\left(N_{i}\right)=\frac{\alpha_{i}^{N_{i}}}{N_{i} !} \exp \left(-\alpha_{i}\right)
$$

where $\alpha_{l}$ is the average admitted traffic intensity of class $i$ in Erlang per cell which is given by 


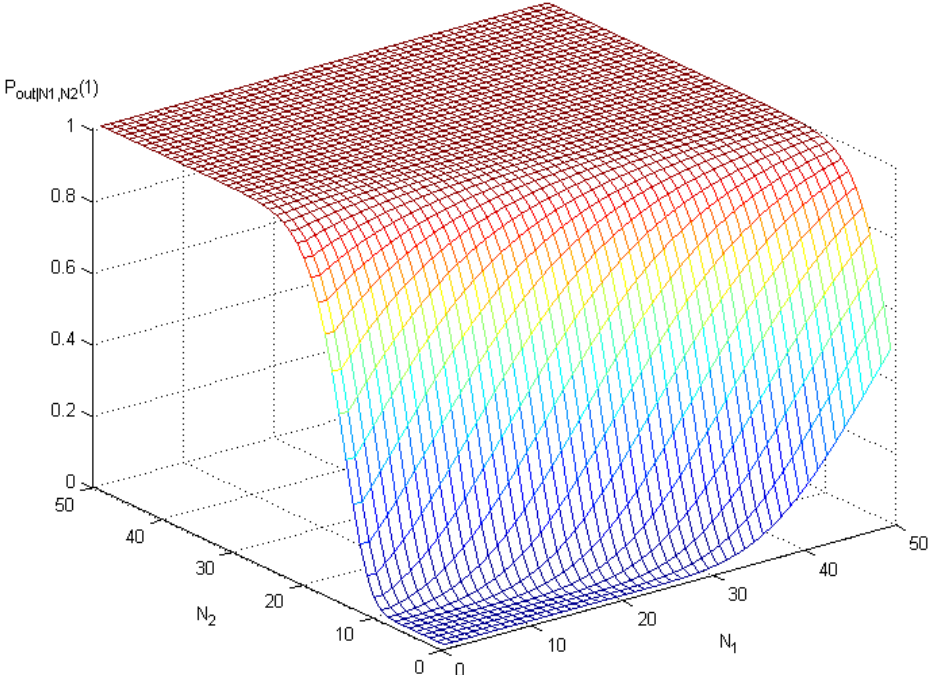

Fig. 2. $\mathrm{P}_{\text {out } \mid \mathrm{N} 1, \mathrm{~N} 2}(1)$ dependence on $N_{l}$ and $N_{2}$ in a dual class CDMA system

$$
\alpha_{i}=\Lambda_{i}\left(1-P_{\mathrm{b}}(i)\right)
$$

where $\Lambda_{i}$ is the average arriving traffic intensity of class $i$ in Erlang per cell and $P_{\mathrm{b}}(i)$ is the blocking probability of class $i$, which is a function of the threshold value of SINR of class $i$ $\left(\operatorname{SINR}_{\mathrm{th}}(i)\right)$ as follows

$$
P_{\mathrm{b}}(i)=1-Q\left(\frac{\operatorname{SINR}_{\mathrm{th}}^{\mathrm{dB}}(i)-m(i)}{\sigma(i)}\right) \text {. }
$$

From (1), (2), (6), (7) and (8) $P_{\text {out }}(i)$ can be expressed as a function of $\operatorname{SINR}_{\mathrm{th}}^{\mathrm{dB}}(j) \forall j \neq i$ as follows

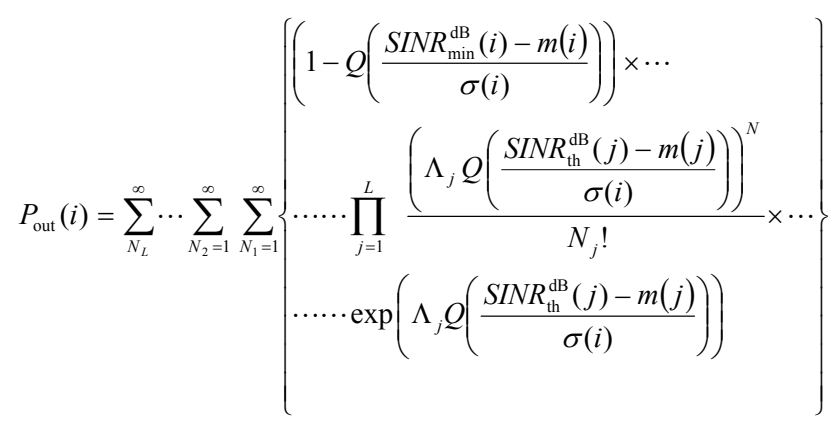

The lower bound of $\operatorname{SINR}_{\mathrm{th}}(i)\left(\operatorname{SINR}_{\mathrm{th} \_\mathrm{b}}(i)\right)$ is determined as the lowest value of $\operatorname{SINR}_{\mathrm{th}}(i)$ that keeps the outage probability of all classes smaller than the corresponding maximum values $\left(P_{\text {out }}(k)<P_{\text {out_max }}(k) k=1,2, \ldots, L\right)$. Since a closed form for $\operatorname{SINR}_{\mathrm{th}-\mathrm{lb}}(i)$ cannot be obtained, $\operatorname{SINR}_{\mathrm{th}-\mathrm{lb}}(i)$ is determined numerically.

\section{RESULTS}

A CDMA system with two classes $(L=2)$ is considered here. The first class $(i=1)$ represents voice service while the second class $(i=2)$ represents video service. The parameters of these two classes are listed in table I.

The dependence of $P_{\text {out }}(1)$ and $P_{\text {out }}(2)$ on $\operatorname{SINR}_{\text {th }}(1)$ and $S I N R_{\text {th }}(2)$ is depicted in Fig. 3 at $\Lambda_{1}=35$ Erlang/cell, $\Lambda_{2}=10$ Erlang/cell, $\operatorname{SINR} R_{\mathrm{th}}(2)=-9 \mathrm{~dB}$ (Fig. $\left.3(\mathrm{a})\right)$ and $\operatorname{SINR}_{\mathrm{th}}(1)=-16 \mathrm{~dB}$ (Fig. 3 (b)). As expected, $P_{\text {out }}(1)$ and $P_{\text {out }}(2)$ increase monotonically with the reduction of $\operatorname{SINR}_{\mathrm{th}}(1)$ or $\operatorname{SINR}_{\mathrm{th}}(2)$. Also, it is apparent that $P_{\text {out }}(1)$ and $P_{\text {out }}(2)$ have a strong dependence on $\operatorname{SINR}_{\mathrm{th}}(1)$ or $\operatorname{SINR}_{\mathrm{th}}(2)$. A 2 or $3 \mathrm{~dB}$ difference in $S_{I N R}$ th $(1)$ or $S I N R_{\text {th }}(2)$ can lead to a one order of magnitude change in $P_{\text {out }}(1)$ and $P_{\text {out }}(2)$. It is clear that $P_{\text {out }}(2)$ is the limiting factor since the lowest value of $\operatorname{SINR}_{\mathrm{th}}(1)$ and $S I N R_{\text {th }}(2)$ (corresponding to $\left.P_{\text {out }}(1)=P_{\text {out }}(2)=P_{\text {out } \max }=0.01\right)$ is imposed by $P_{\text {out }}(2)$. This is not surprisong since class 2 (video service) has higher $S I N R_{\min }$ as shown in Table I. However, this is not always the case. For instance, if $P_{\text {out max }}$ of any (or both) of the two classes is increased to 0.013 (or higher), $P_{\text {out }}(1)$ will be the limiting factor for $\operatorname{SINR}_{\mathrm{th}}(1)$ as shown in Fig. 3 (a). In fact, which service class is the limiting factor for $S I N R_{\text {th }}$ is dependent on the loading value of the two classes, $S I N R_{\text {th }}$ of the other class, $P_{\text {out max }}$ of both classes and the relative values of $S_{I N R_{\min }}$ of both classes.

Figs. 4 and 5 depict $\operatorname{SINR}_{\text {th-lb }}(1)$ versus $\Lambda_{1}$ and $\Lambda_{2}$ at $S I N R_{\mathrm{th}}(2)=-10 \mathrm{~dB}$ and $-9 \mathrm{~dB}$ respectively. As expected, $S I N R_{\text {th- }}$ ${ }_{\mathrm{lb}}(1)$ is a monotonically increasing functions of both $\Lambda_{1}$ and $\Lambda_{2}$. However, $\operatorname{SINR}_{\mathrm{th}-\mathrm{lb}}(1)$ has less dependence on $\Lambda_{2}$ at $\operatorname{SINR} R_{\mathrm{th}}(2)=$ $9 \mathrm{~dB}$ than that at $\operatorname{SINR}_{\mathrm{th}}(2)=-10 \mathrm{~dB}$. This is because when $\operatorname{SINR}_{\mathrm{th}}(2)=-9 \mathrm{~dB}$, high blocking rate is encountered by class 2 users. Therefore, changing $\Lambda_{2}$ does not have a strong impact on the outage probabilities of the two classes $\left(P_{\text {out }}(1)\right.$ and $\left.P_{\text {out }}(2)\right)$. Also, it is apparent that the dependence of $\operatorname{SINR}_{\mathrm{th}-\mathrm{lb}}(1)$ on $\Lambda_{1}$ is higher at lower values of $\Lambda_{2}$. For instance, at $\Lambda_{2}=5 \operatorname{SINR}_{\text {th-lb }}(1)$ increases from $-17.5 \mathrm{~dB}$ to $-16.8 \mathrm{~dB}$ by increasing $\Lambda_{1}$ from 30 to 40 Erlang/cell, while at $\Lambda_{2}=40, \operatorname{SINR}_{\text {th-lb }}(1)$ increases from $16.3 \mathrm{~dB}$ to $-16.0 \mathrm{~dB}$ by increasing $\Lambda_{1}$ from 30 to 40 Erlang/cell. It is also evident that for some ranges of $\Lambda_{1}$ and $\Lambda_{2}$, there is no finite value for $\operatorname{SINR}_{\mathrm{th}-\mathrm{lb}}(1)$. For example, at small values of $\Lambda_{1}$ and $\Lambda_{2}$ there is no need for any bound (i.e. $\operatorname{SINR}_{\mathrm{th}-\mathrm{lb}}(1)=-\infty \mathrm{dB}$ ) since it is possible to admit all arrival traffic without violating the constraints on the outage probabilities $\left(P_{\text {out }}(1)<P_{\text {out } \max }(1)\right.$ and $\left.P_{\text {out }}(2)<P_{\text {out_max }}(2)\right)$. On the other hand, at large values of $\Lambda_{2}\left(>25\right.$ Erlang/cell) at $\operatorname{SINR}_{\mathrm{th}}(2)=-10 \mathrm{~dB}$, it is found that the outage constraints of class 2 users $\left(P_{\text {out }}(2)\right)$ becomes higher than the maximum value $\left(P_{\text {out_max }}(2)\right)$ regardless of the value of $S I N R_{\text {th-lb }}(1)$ (i.e. $\left.\operatorname{SINR}_{\mathrm{th}-\mathrm{lb}}(1)=\bar{\infty} \mathrm{dB}\right)$.

TABLE I. PARAMETERS OF THE TWO CLASSES OF SERVICE

\begin{tabular}{|c|c|c|}
\hline Parameter & Voice & Video \\
\hline Transmission rate & $16 \mathrm{kbps}$ & $64 \mathrm{kbps}$ \\
\hline Minimum SINR $\left(\right.$ SINR $\left._{\min }\right)$ & $-18 \mathrm{~dB}$ & $-12 \mathrm{~dB}$ \\
\hline Target SINR $\left(\right.$ SINR $\left._{\text {trg }}\right)$ & $-12 \mathrm{~dB}$ & $-6 \mathrm{~dB}$ \\
\hline Maximum outage Probability $\left(P_{\text {out }}{ }_{\max }\right)$ & $1 \%$ & $1 \%$ \\
\hline Standard deviation of SINR $(\sigma)$ & $1 \mathrm{~dB}$ & $1 \mathrm{~dB}$ \\
\hline
\end{tabular}




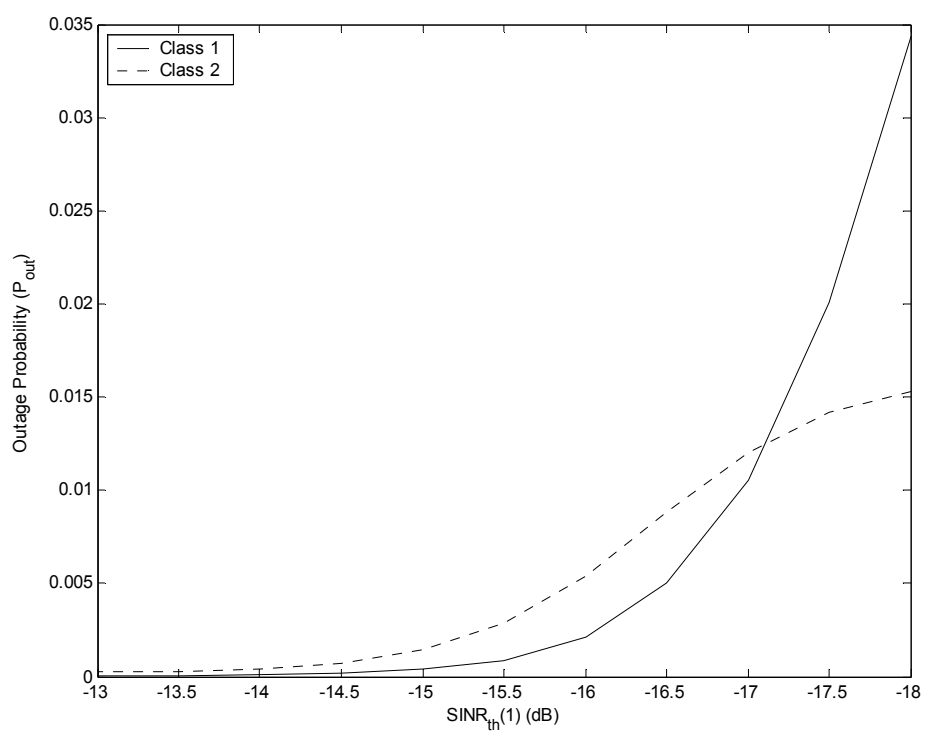

(a)

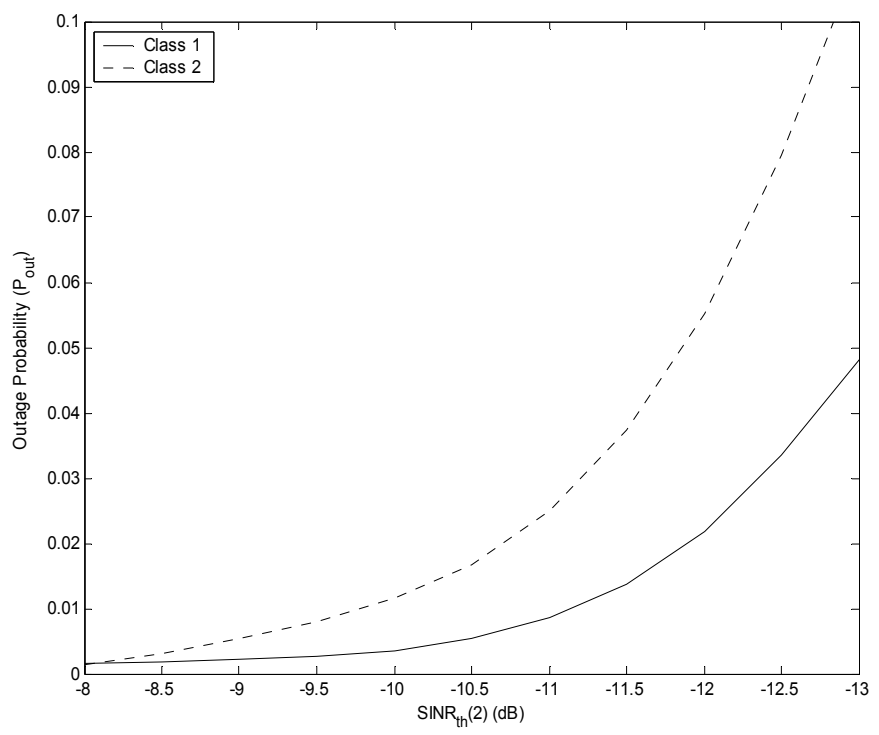

(b)

Fig. 3. Outage probabilities dependence (a) on $\operatorname{SINR}_{\mathrm{th}}(1)$ at $\operatorname{SINR} R_{\mathrm{th}}(2)=-9 \mathrm{~dB}$ and (b) on $\operatorname{SINR} R_{\mathrm{th}}(2)$ at $\operatorname{SINR} R_{\mathrm{th}}(1)=-16 \mathrm{~dB}$.

Similar trends can also be observed in Figs. 6 and 7 for $\operatorname{SINR}_{\mathrm{th}-\mathrm{lb}}(2)$ at $\operatorname{SINR}_{\mathrm{th}}(1)=-16 \mathrm{~dB}$ and $-14 \mathrm{~dB}$ respectively. For instance, $S I N R_{\mathrm{th}-\mathrm{lb}}(2)$ shows less dependence on $\Lambda_{1}$ at $\operatorname{SINR}_{\mathrm{th}}(1)=-14 \mathrm{~dB}$ than that at $\operatorname{SINR}_{\mathrm{th}}(1)=-16 \mathrm{~dB}$. For example at $\Lambda_{2}=10$ Erlang/cell, $\operatorname{SINR}_{\mathrm{th}-\mathrm{bl}}(2)$ increases from $-10.8 \mathrm{~dB}$ to $9.6 \mathrm{~dB}$ by increasing $\Lambda_{1}$ from 5 to 40 Erlang/cell at $\operatorname{SINR}_{\mathrm{th}}(1)=-16 \mathrm{~dB}$, while $\operatorname{SINR}_{\mathrm{th}-\mathrm{lb}}(2)$ changes from -11 to $10.9 \mathrm{~dB}$ for the same increase in $\Lambda_{1}$ at $\operatorname{SINR}_{\mathrm{th}}(1)=-14 \mathrm{~dB}$. Also, it is apparent that for small values of $\Lambda_{1}$ and $\Lambda_{2}$, there is no need for any bound on $\operatorname{SINR}_{\mathrm{th}}(2)\left(\operatorname{SINR}_{\mathrm{th}-\mathrm{lb}}(2)=-\infty \mathrm{dB}\right)$. For example in Fig. 7, for $\Lambda_{2}<10$ Erlang/cell all arriving users can be admitted without violating the constraints on the outage probabilities $\left(P_{\text {out }}(1)<P_{\text {out_max }}(1)\right.$ and $\left.P_{\text {out }}(2)<P_{\text {out_max }}(2)\right)$.

These results show that when stringent admission conditions are imposed on the traffic of a certain class, the change of the traffic intensity of this class does not have a strong impact on the value of $S I N R_{\mathrm{th}-1 \mathrm{~b}}$. Moreover, the results show that at low values of traffic intensity, the constraints on the outage probability can be guaranteed without imposing any constraints on $S I N R_{\mathrm{th}}$.

\section{CONCLUSIONS}

A lower bound of $\operatorname{SINR}_{\mathrm{th}}\left(\operatorname{SINR}_{\mathrm{th}-\mathrm{lb}}\right)$ has been derived in multi-class CDMA systems with imperfect power control. $S I N R_{\text {th } 1 \mathrm{~b}}$ is determined by finding the relationship between $P_{\text {out }}$ and $\operatorname{SIN} R_{\mathrm{th}}$ of all classes and then finding the lowest value of $S I N R_{\text {th }}$ that keeps all outage probabilities $\left(P_{\text {out }}(\mathrm{i}), i=1,2, \ldots, L\right)$ below the corresponding maximum values $\left(P_{\text {out } \max }\right)$. The analysis is developed for any number of classes $(L)$. However, the numeric results are obtained for a dual class system $(L=2)$. It is assumed that outage occurs due to power control infeasibility and SINR fluctuation due to imperfect power control. $S I N R_{\text {th-lb }}$ has been determined for a CDMA system with two classes of service. Furthermore, the dependence of $S I N R_{\text {th-lb }}$ on the traffic arrival intensity of different classes has been analyzed. Results show that $S I N R_{\text {th-lb }}$ is vital to keep the outage probability below the maximum value. Furthermore, results indicate that the value of $S I N R_{\text {th-lb }}$ of some class is strongly dependent on the traffic intensity of this class and to some extent on the traffic intensity of other classes as well. Finding an upper bound of SINR for multiple-class CDMA will be considered in future work.

\section{REFERENCES}

[1] Z. Liu and M. El Zarki, "SIR-based call admission control for DSCDMA cellular systems," IEEE Journal on Selected Areas in Commun. (JSAC), vol. 12, no. 4, May 1994, pp. 638-644.

[2] I.-M. Kim, B.-C. Shin, and D. Lee, "SIR-based call admission control by intercell interference prediction for DS-CDMA systems," IEEE Communications Letters, vol. 4, no. 1, Jan. 2000, pp. 29-31.

[3] A. Viterbi and A. Viterbi, "Erlang capacity of a power controlled CDMA system," IEEE Journal on Selected Areas in Communications (JSAC), vol. 11, no. 6, Aug. 1993, pp. 892-900.

[4] S. Ariyavisitakul and L. Chang, "Signal and interference statistics of a CDMA system with feedback power control", IEEE Trans. on Communications, vol. 49, Feb. 2001, pp. 249-252.

[5] D. Kim, "On upper bounds of SIR-based call admission threshold in power-controlled DS-CDMA mobile systems", IEEE Communications Letters, vol. 6, no. 1, Jan. 2002, pp. 13 -15.

[6] M. Ahmed and H. Yanikomeroglu, "SINR threshold lower bound for SINR-based call admission control in CDMA networks with imperfect power control", submitted to IEEE Communication Letters.

[7] M. Ahmed, H. Yanikomeroglu, and B. Hashem, "Radio Resource Management in Wireless Multimedia Networks", IEEE Globecom'02 (tutorial).

[8] A. Sampath, P. Kumar, and J. Holtzman, "Power control and resource management for a multimedia CDMA wireless system", IEEE International Symposium on Personal, Indoor and Mobile Communications (PIMRC'95), 1995, pp. 21-25. 


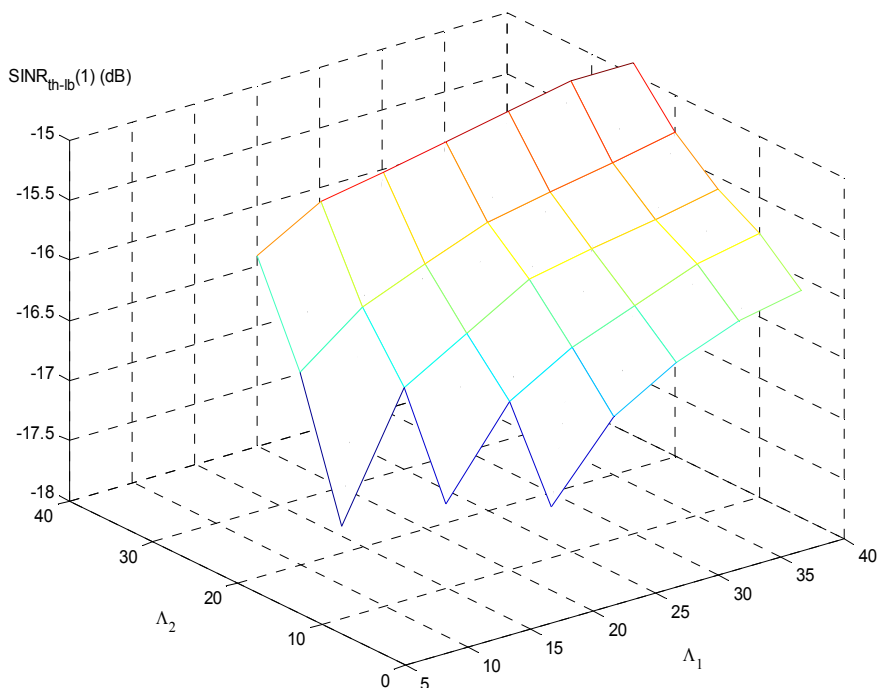

Fig.4. $\operatorname{SINR} R_{\mathrm{th}-\mathrm{bl}}(1)$ dependence on $\Lambda_{1}$ and $\Lambda_{2}\left(\operatorname{SINR}_{\mathrm{th}}(2)=-10 \mathrm{~dB}\right)$

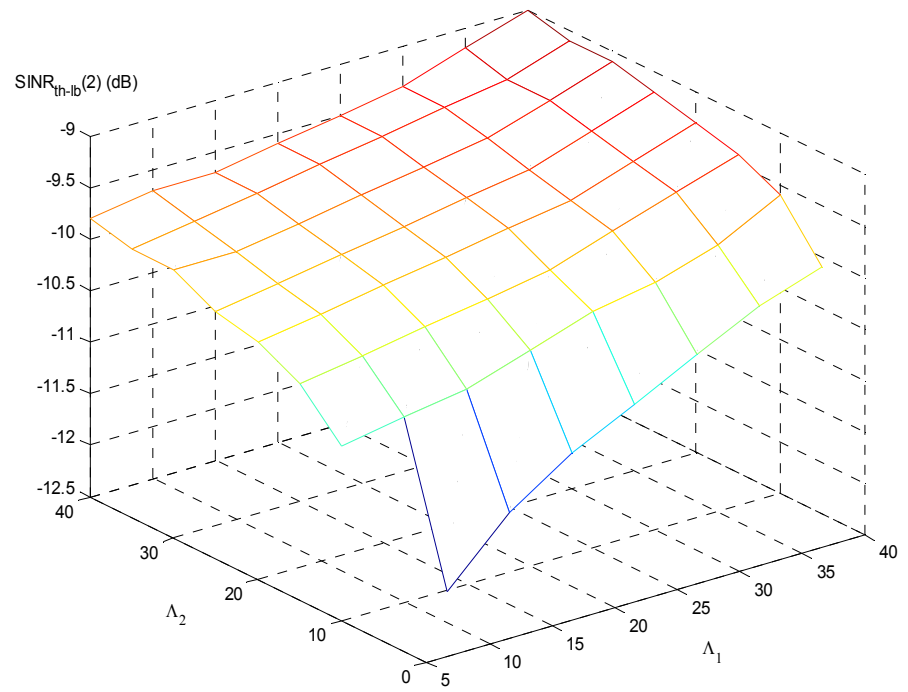

Fig.6. $\operatorname{SINR}_{\mathrm{th}-\mathrm{b}}(2)$ dependence on $\Lambda_{1}$ and $\Lambda_{2}\left(\operatorname{SINR}_{\mathrm{th}}(1)=-16 \mathrm{~dB}\right)$

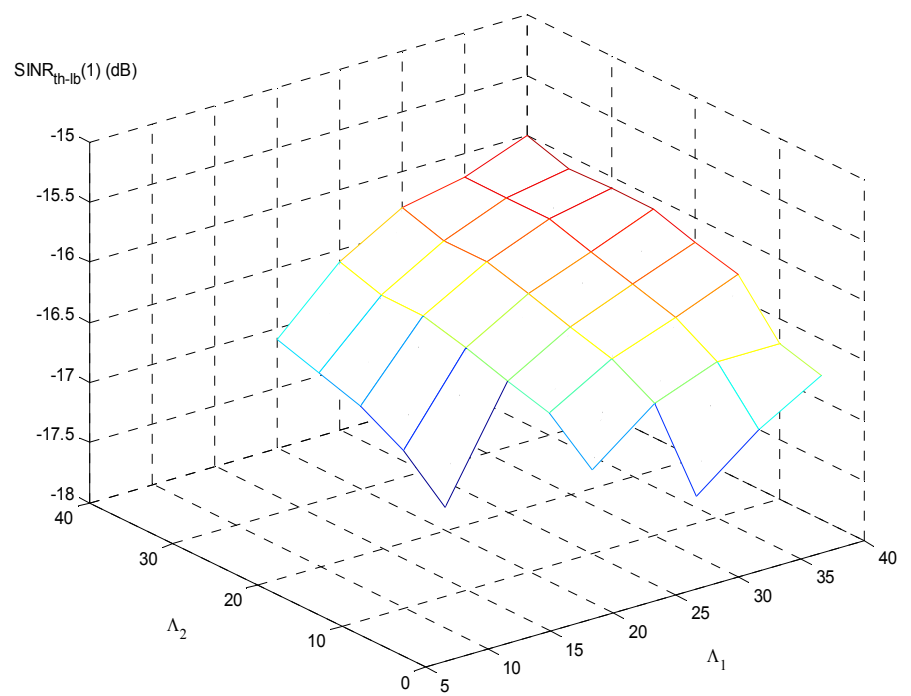

Fig.5. $\operatorname{SINR}_{\mathrm{th}-\mathrm{lb}}(1)$ dependence on $\Lambda_{1}$ and $\Lambda_{2}\left(\operatorname{SINR}_{\mathrm{th}}(2)=-9 \mathrm{~dB}\right)$

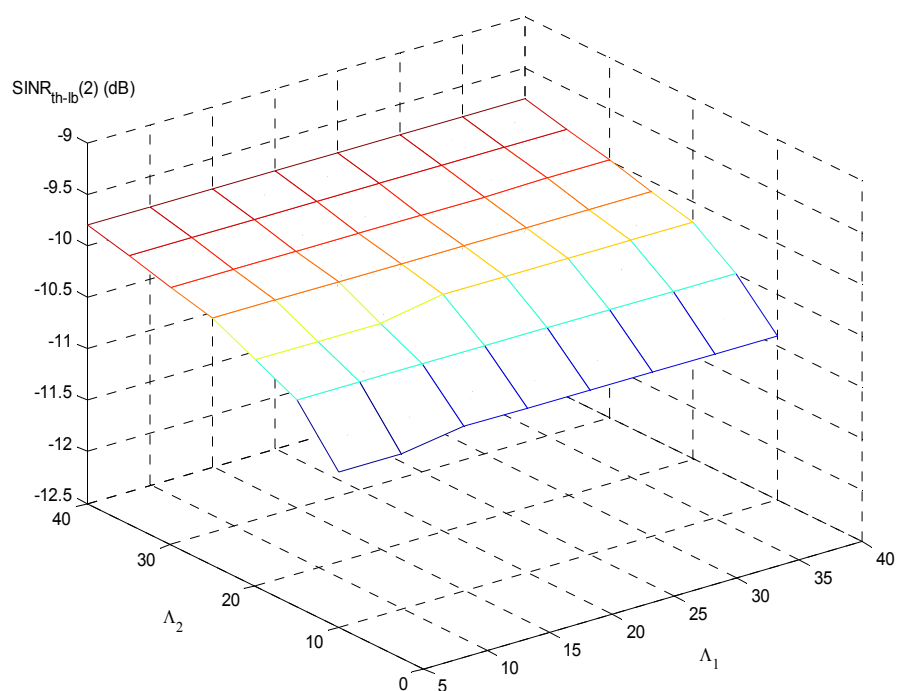

Fig.7. $\operatorname{SINR} R_{\mathrm{th}-\mathrm{lb}}(2)$ dependence on $\Lambda_{1}$ and $\Lambda_{2}\left(\operatorname{SINR}_{\mathrm{th}}(1)=-14 \mathrm{~dB}\right)$ 